\title{
EFFect of Process Parameters on Dimensional ACCURACY ANd Tensile STREngth OF FDM Printed Parts
}

\author{
Ahmet Cekic, Kenan Muhamedagic, Derzija Begic-Hajdarevic \& Nejra Djuzo
}
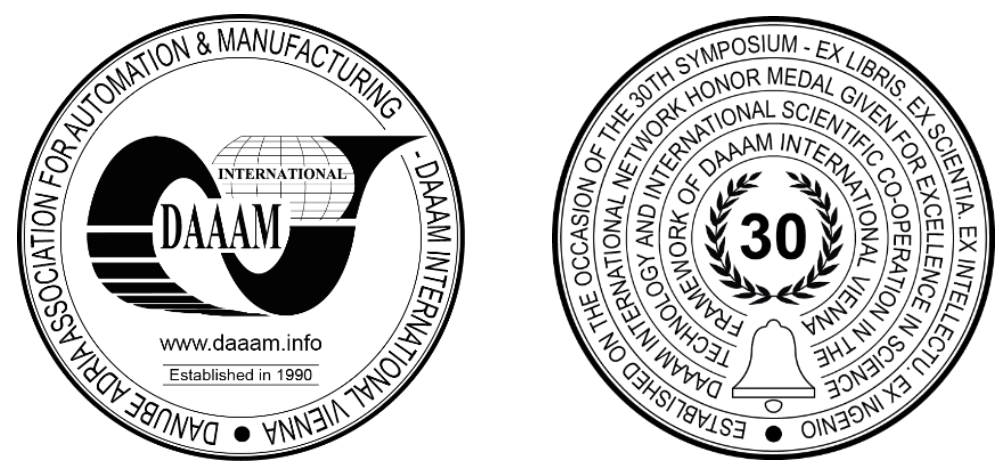

This Publication has to be referred as: Cekic, A[hmet]; Muhamedagic, K[enan]; Begic-Hajdarevic, D[erzija] \& Djuzo, N[ejra] (2020). Effect of Process Parameters on Dimensional Accuracy and Tensile Strength of FDM Printed Parts, Proceedings of the 31st DAAAM International Symposium, pp.0066-0071, B. Katalinic (Ed.), Published by DAAAM International, ISBN 978-3-902734-29-7, ISSN 1726-9679, Vienna, Austria

DOI: $10.2507 / 31$ st.daaam.proceedings.009

\begin{abstract}
Fused Deposition Modeling (FDM) is one of the most popular additive manufacturing technologies for various engineering applications. Due to the mechanism of building of products on the principle of adding layer by layer, the mechanical characteristics and quality of the product directly depend on the values of process parameters. Therefore, in this paper, test tubes for mechanical properties testing and model samples for dimensional testing were made using FDM technology. Two different polymeric materials, PLA and PC, were used to make the tubes and models. During the production of test tubes and models, three more influential process parameters varied on three levels: printing temperature, infill density and layer height. The test tubes were printed and tensile tested according to the ISO 527-2 standard. Dimensional measurements were performed on the made samples of models for dimensional tests, and dimensional deviations of the finished product in relation to the designed dimensions of the 3D model were analyzed, deviations from the shape, as well as the presence of surface defects and irregularities. At the end of the paper, recommendations are given which combination of process parameters gives for both analyzed materials better mechanical characteristics and smaller dimensional deviations of the product in the manufacture of FDM technology.
\end{abstract}

Keywords: FDM; Process parameters; Additive manufacturing; Dimensional accuracy; Tensile strength.

\section{Introduction}

Additive technologies enable fast and efficient creation of very complex physical models on the principle of adding material "layer by layer" directly from the CAD program. One of the most commonly used additive processes is the FDM process. Fused deposition modelling (FDM) is one of the additive manufacturing (AM) techniques generally used to rapid prototyping, rapid tooling and fabricate direct end-use parts. FDM is capable of producing accurate and durable functional 3D parts using plastic materials such as acrylonitrile butadiene styrene (ABS), polylactic acid (PLA), poly carbonate (PC), polyethylene terephthalate (PET), thermoplastic polyurethane (TPU), Nylon, etc. In order to take advantage of this technology, it is necessary to optimize a large number of influential process parameters for each material used. Namely, the process parameters of the FDM process directly affect the product quality and mechanical characteristics and are the subject of research by many authors [1][2]. 
This paper provides an extensive overview of the optimization of process parameters of the FDM process and allows focusing on achieving higher accuracy products, surface quality and mechanical properties of the final product. Namely, product quality, surface roughness and mechanical properties depend on printing parameters such as: layer height, infill style and density, number of horizontal layers of the model, printing temperature, properties of the material used during printing, orientation of the model, use support structures, etc. [6][7][8][9]. In addition to the above, the process parameters are also affected by the quality of STL file, slicing tools, and the quality and capabilities of the FDM device [3][4]. It is considered that the optimal setting of parameters improves the quality of three-dimensional printed parts and can reduce the need for finishing parts. The basic process parameters during the production by FDM / FFF process are: nozzle diameter, layer height, and nozzle temperature, i.e. printing temperature, infill density and printing speed. Each of these parameters can be manually changed and customized using the appropriate 3D printer software, but it should know that the 3D printing software itself also offers the ability to automatically determine the parameters. FDM technology uses coil-shaped thermoplastics wound on spools, usually $1.75 \mathrm{~mm}$ or $2.85 \mathrm{~mm}$ in diameter. For the selected material, a very important parameter is the choice of the printing temperature and temperature of work surface, and in connection with that, the choice of other parameters such as the thickness of the layers, infill density, the printing speed, etc. Each material has a different composition and the melting temperature depends on it. The melting temperature of the material sometimes differs even for the same material from the same manufacturer and different colours [5]. In this paper, the optimal printing temperatures were determined, together with two other important parameters (layer thickness and filling percentage), for two most used materials in the FDM process, namely PLA and PC material.

\section{Experimental procedure}

To investigate and define the optimal process parameters in the FDM process, two different materials were used, PolyCarbonate - PC and PolyLactic Acid - PLA material from manufacturer "3D Republika" and diameter of filament wire is $2,85 \mathrm{~mm}$ for Ultimaker S5 3D printer. The following process parameters were varied: printing temperature, infill type and percentage, and layer height. Fixed parameters are as follows: print speed $(50 \mathrm{~mm} / \mathrm{s})$ and work surface temperature $\left(60^{\circ} \mathrm{C}\right.$ for PLA material, $110^{\circ} \mathrm{C}$ for PC material). In addition, both materials are printed on the Ultimaker S5 device. The plan of the experiment is given in Table 1, and the CAD model of the test tube for tensile testing is given in Figure 1a, and 3D model for dimensional accuracy testing on Figure 1b.

\begin{tabular}{|c|c|c|c|c|c|}
\hline $\begin{array}{l}\text { Test sample } \\
\text { (PLA) }\end{array}$ & $\begin{array}{l}\text { Test sample } \\
\text { (PC) }\end{array}$ & $\begin{array}{c}\text { Layer } \\
\text { thickness }(\mathrm{mm})\end{array}$ & $\begin{array}{c}\text { Infill density } \\
(\%)\end{array}$ & $\begin{array}{l}\text { Printing temperature } \\
\text { for PLA }\left({ }^{\circ} \mathrm{C}\right)\end{array}$ & $\begin{array}{l}\text { Printing temperature } \\
\text { for } \mathrm{PC}\left({ }^{\circ} \mathrm{C}\right)\end{array}$ \\
\hline 1. PLA & 1. PC & 0,2 & 100 & 230 & 280 \\
\hline 2. PLA & 2. $\mathrm{PC}$ & 0,1 & 100 & 170 & 230 \\
\hline 3. PLA & 3. PC & 0,15 & 100 & 230 & 280 \\
\hline 4. PLA & 4. $\mathrm{PC}$ & 0,15 & 20 & 230 & 280 \\
\hline 5. PLA & 5. PC & 0,1 & 100 & 200 & 255 \\
\hline 6. PLA & 6. PC & 0,2 & 60 & 200 & 255 \\
\hline 7. PLA & 7. $\mathrm{PC}$ & 0,15 & 100 & 170 & 230 \\
\hline 8. PLA & 8. PC & 0,1 & 60 & 230 & 280 \\
\hline 9. PLA & 9. PC & 0,2 & 60 & 230 & 280 \\
\hline 10. PLA & 10. PC & 0,1 & 20 & 230 & 280 \\
\hline 11. PLA & 11. PC & 0,1 & 100 & 230 & 280 \\
\hline 12. PLA & 12. PC & 0,1 & 20 & 170 & 230 \\
\hline 13. PLA & 13. PC & 0,2 & 20 & 200 & 255 \\
\hline 14. PLA & 14. PC & 0,1 & 60 & 170 & 230 \\
\hline 15. PLA & 15. PC & 0,2 & 100 & 170 & 230 \\
\hline 16. PLA & 16. PC & 0,15 & 100 & 200 & 255 \\
\hline 17. PLA & 17. PC & 0,15 & 60 & 230 & 280 \\
\hline 18. PLA & 18. PC & 0,15 & 20 & 200 & 255 \\
\hline 19. PLA & 19. PC & 0,2 & 60 & 170 & 230 \\
\hline 20. PLA & 20. PC & 0,2 & 20 & 230 & 280 \\
\hline 21. PLA & 21. PC & 0,2 & 100 & 200 & 255 \\
\hline 22. PLA & 22. PC & 0,15 & 60 & 170 & 230 \\
\hline 23. PLA & 23. PC & 0,15 & 60 & 200 & 255 \\
\hline 24. PLA & 24. PC & 0,1 & 60 & 200 & 255 \\
\hline 25. PLA & 25. PC & 0,2 & 20 & 170 & 230 \\
\hline 26. PLA & 26. PC & 0,1 & 20 & 200 & 255 \\
\hline 27. PLA & 27. PC & 0,15 & 20 & 170 & 230 \\
\hline
\end{tabular}

Table 1. Experimental runs for PLA and PC material 


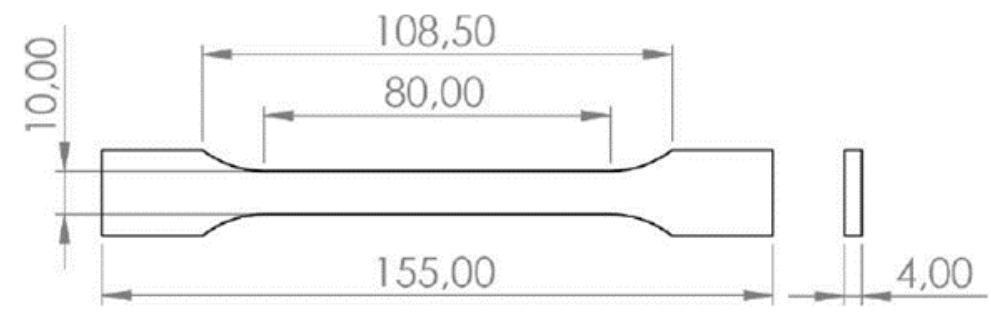

Fig. 1a. Dimensions of the specimen according to ISO 527-2

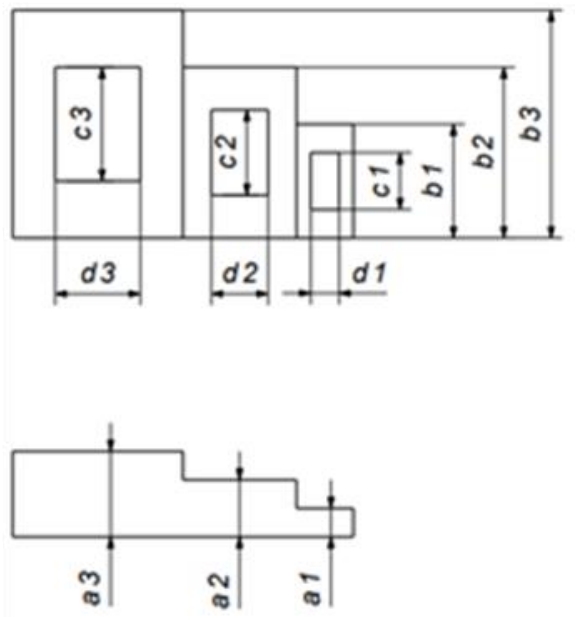

Fig. 1b. Layout of model for dimensional testing

A $0.4 \mathrm{~mm}$ diameter nozzle was used for printing. To ensure minimal buckling of the printed model, as well as good adhesion to the work surface, an adhesive was used, which was applied to the work surface. The models were printed without supporting structures, as well as without the so-called "Brim" options.

A test tube of rectangular cross - section of shape E, the dimensions of which are given in Figure 1a. according to EN ISO 527-2, was used to tensile testing. In order to reduce the influence of the position of the test tube on the working surface of the 3D printer, the test tubes were printed in a series of 3 pieces, the same temperature and layer height, and a different percentage of infill density. The test of the test tubes was performed by the classical test on a tensile tester Shimazu AGS-X, according to the set plan of the experiment. 27 tubes of PLA material and 27 tubes of PC material were tested, which were made with the process parameters given in Table 1.

\subsection{Experimental equipment}

After printing a total of 54 tubes for tensile testing and 54 samples of models for dimensional accuracy testing, they were tested using measuring equipment located in the laboratories of the Department of Mechanical Production Engineering at the Faculty of Mechanical Engineering, University of Sarajevo. The test samples were tested on a tensile tester Shimadzu AGS-X, with a constant deformation rate and using dedicated data processing software (Trapezium Lite $\mathrm{X}$ ). During the tensile testing, the deformation rate of the specimens was $5 \mathrm{~mm} / \mathrm{s}$. In addition to the tensile test specimens, test samples for dimensional accuracy testing were made with the same process parameters in order to test the dimensional deviations from the designed CAD model and determine the optimal process parameters. Measurement of test samples for dimensional accuracy testing was performed on a universal two-coordinate measuring microscope ZKM 01-250C and with the micrometre for measuring external measurements with an accuracy of $0.01 \mathrm{~mm}$.

\section{Results and Discussions}

\subsection{The influence of the printing temperature on the dimensional accuracy}

In order to examine how the printing temperature affects the dimensional accuracy, as well as deviations from the designed dimensions, models with variations of three process parameters were made: printing temperature, layer height and infill density, which makes a total of 27 specimens of PLA material and 27 of PC material. The internal dimensions of the model, marked with $\mathrm{c} 1 \mathrm{xd} 1, \mathrm{c} 2 \mathrm{xd} 2$ and $\mathrm{c} 3 \mathrm{xd} 3$, and the external dimensions of the model marked with a1, a2, a3, b1, b2 and b3 were measured (Figure 2.). As a result of measuring the internal dimensions, it is concluded that all measured deviations are negative, ie less than the values of the dimensions designed by the CAD model. The smallest measured deviation of the internal dimensions is $0.18 \mathrm{~mm}$ (sample $21 \mathrm{PLA}$ ), and the largest $0.83 \mathrm{~mm}$ (sample 16 PC). 
Figure 2a. shows the influence of the printing temperature on the average value of the deviation of external dimensions for PLA material, where it is concluded that the model has the smallest deviation in the direction of dimensions $a 1, a 2$ and $a 3$ if printed at a temperature of $200-230{ }^{\circ} \mathrm{C}$, which also belongs to the recommended printing temperature by the material manufacturer. Figure $2 \mathrm{~b}$. shows the influence of the printing temperature on the average value of the deviation of external dimensions for PC material, where it is concluded that the model has the smallest deviation in the direction of dimensions $a 1, a 2$ and $a 3$ if printed at a temperature from $255-280{ }^{\circ} \mathrm{C}$, which also belongs to the recommended printing temperature by the material manufacturer, except for the largest dimension $a 3$ where the smallest dimensional deviations in the temperature range from 230 to $255^{\circ} \mathrm{C}$.

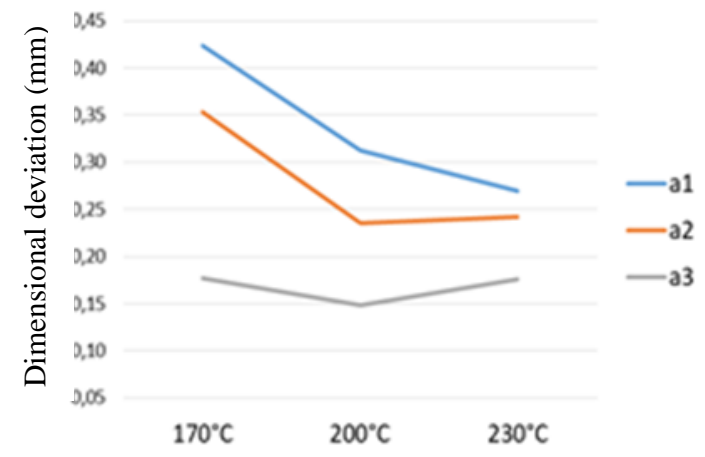

a)

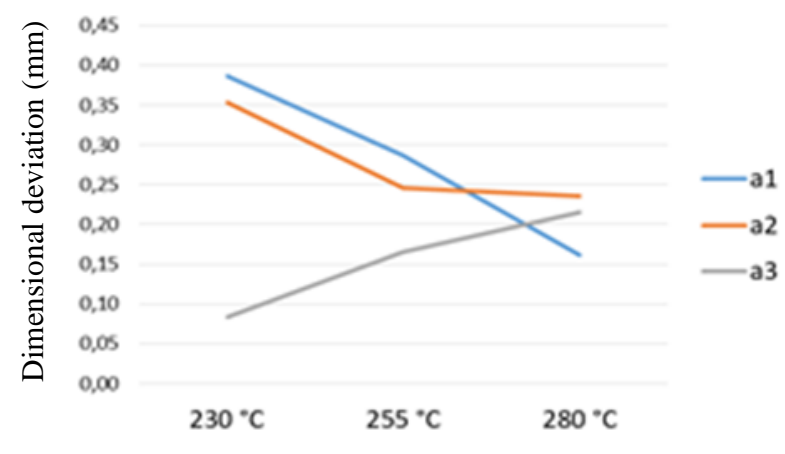

b)

Fig. 2. Influence of printing temperature on the dimensional deviations for PLA (a) and PC material (b)

\subsection{The influence of the layer thickness on the dimensional accuracy}

Layer thickens is a very important process parameter when making a product. To examine the influence of layer height on dimensional accuracy, samples with three different layer heights were made: $0.10 \mathrm{~mm}, 0.15 \mathrm{~mm}$ and $0.20 \mathrm{~mm}$, where the print speed was fixed, and the printing temperature and infill density were varied in accordance with the setting of the experiment plan.

By processing the results, it was concluded that all deviations are negative (model dimensions are smaller than the designed dimensions on the CAD model) at smaller dimensions ( $5 \mathrm{~mm}, 10 \mathrm{~mm}, 15 \mathrm{~mm}, 20 \mathrm{~mm}$ ), while larger dimensions of the printed model $(40 \mathrm{~mm}$ ) had positive deviations (model dimensions are bigger than the designed dimensions on the CAD model). The influence of layer thickness on dimensional deviations for PLA and PC material is shown in Figure 3.

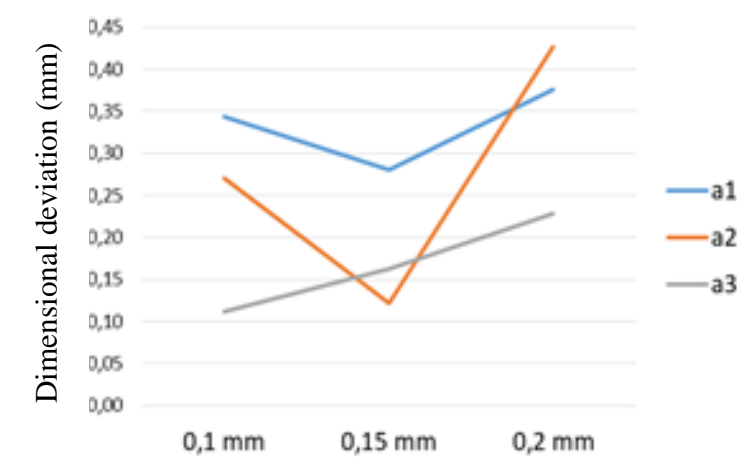

a)

Fig. 3. Influence of layer thickness on the dimensional deviations for PLA (a) and PC material (b)

\subsection{The influence of process parameters on the tensile strength}

The analysis of the following diagrams leads to the conclusion which of the three varied process parameters has the significant effect on the tensile strength. Figure 5 shows the effect of printing temperature and layer thickness on the tensile strength of PLA and PC materials. The highest value of tensile strength is achieved for smaller layer thicknesses $(0.1 \mathrm{~mm}$ and $0.15 \mathrm{~mm})$ and higher values of printing temperatures $\left(200-230{ }^{\circ} \mathrm{C}\right.$ for PLA material and $255-280{ }^{\circ} \mathrm{C}$ for PC material). 


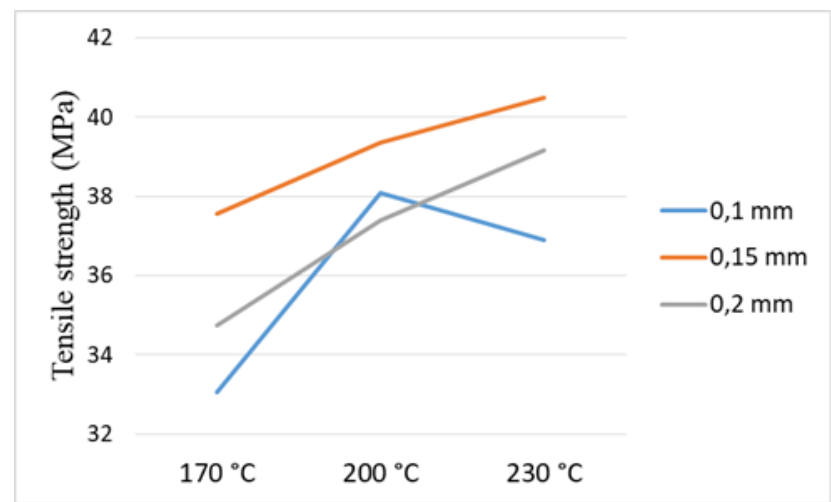

a)

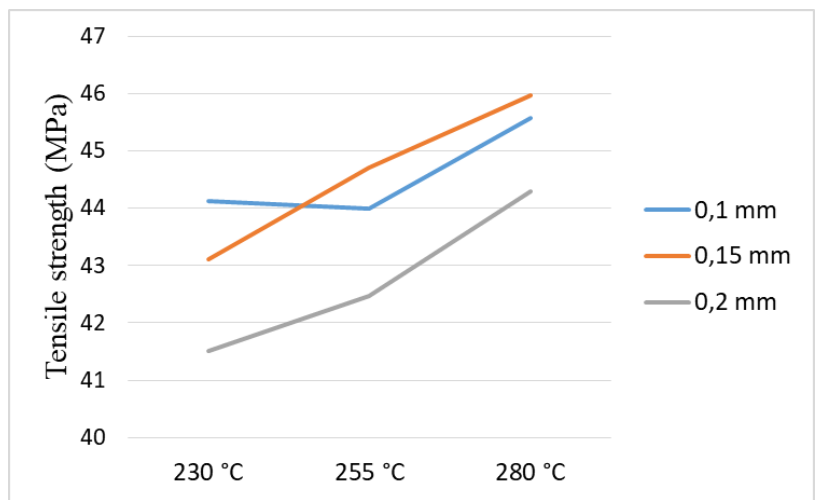

b)

Fig. 4. The influence of printing temperature and layer thickness on the tensile strength

Figure 5. shows the effect of the infill density on the tensile strength. The analysis of the diagram concludes that the infill density has the most significant effect on the tensile strength, in relation to the other two process parameters, the printing temperature and the layer thickness. Printing with a set infill density of $100 \%$ gives a significantly higher value of tensile strengths, compared to printing with a infill density of $20 \%$ and $60 \%$. It was also noticed that the difference between the percentage of fillings of $20 \%$ and $60 \%$ is not significant, and therefore it is recommended to print at a infill density of $20 \%$, because the production time is much shorter and material consumption is lower.

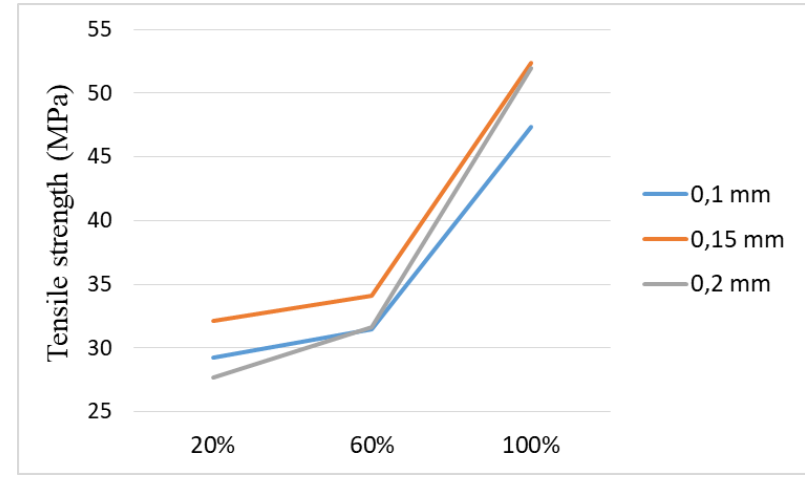

a)

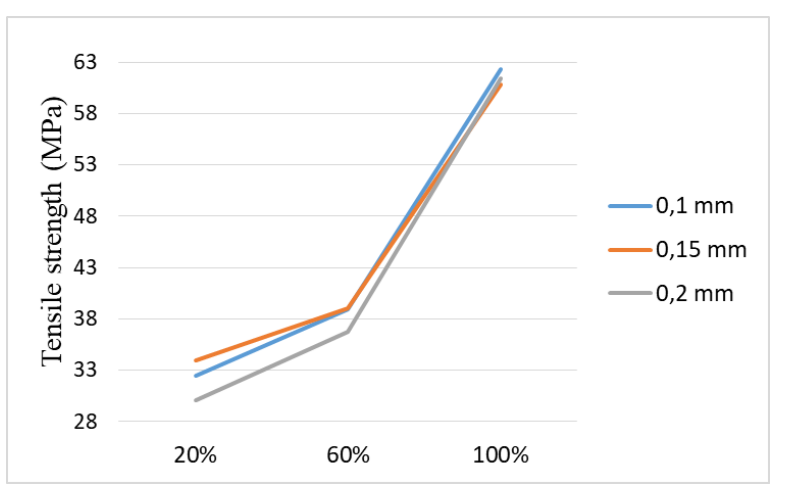

b)

Fig. 5. The influence of infill density and layer thickness on the tensile strength

\section{Conclusion}

The paper experimentally investigates the relationship between the process parameters of production and the quality of the final product. By varying the process parameters: printing temperature, layer thickness and infill density, optimal process parameters were obtained with which it is possible to obtain a product of satisfactory surface quality, smaller dimensional deviations from the CAD model, and higher tensile strength values.

After the measurement, it was concluded that the process parameter that most affects the value of tensile strength is the infill density, and the process parameter that least affects the value of tensile strength is the printing temperature. The optimal process parameters for PLA material with respect to tensile strength and dimensional accuracy are: printing temperature $200{ }^{\circ} \mathrm{C}$, layer thickness $0.15 \mathrm{~mm}$, infill density $100 \%$, and for PC material: printing temperature $255^{\circ} \mathrm{C}$, layer thickness $0.15 \mathrm{~mm}$ and infill density $100 \%$. Both of these optimal temperatures are within the recommended print temperature range of the material manufacturer. To achieve dimensional accuracy, experimental analysis showed that for PLA material a layer height of $0.15 \mathrm{~mm}$, a infill density of $20 \%$ or $60 \%$ and a printing temperature of $200{ }^{\circ} \mathrm{C}$ affect smaller dimensional deviations of the printed models compared to the designed CAD model. For PC material, the optimal parameters for smaller dimensional deviations are: layer height $0.15 \mathrm{~mm}$, infill density $60 \%$ and printing temperature 255 ${ }^{\circ} \mathrm{C}$.

How the infill density is the most significant parameter for the tensile strength value, and how this process parameter most influences the printing time and the amount of consumed material, for a clearer picture and better understanding of the impact of the infill density on tensile strength values for future research a more detailed examination of the impact of the infill density in the interval from $10 \%$ to $100 \%$ is planned. 


\section{Acknowledgments}

The authors of this paper are grateful to UNDP and the Embassy of Sweden for the donated equipment (3D printers) with which part of the experimental research within this paper was conducted.

\section{References}

[1] Cekic, A.; Begic-Hajdarevic, D.; Cohodar, M.; Muhamedagic, K. \& Osmanlic, M. (2019). Optimization of Stereolithography and Fused Deposition Modeling Process Parameters, Proceedings of the 30th DAAAM International Symposium, pp.0681-0687, B. Katalinic (Ed.), Published by DAAAM International, ISBN 978-3902734-22-8, ISSN 1726-9679, Vienna, Austria DOI: 10.2507/30th.daaam.proceedings.093

[2] Cekic, A.; Begic-Hajdarevic, D.; Muhamedagic, K. \& Guzanovic, N. (2018). Experimental Investigations of Process Parameters Influence on Dimensional Accuracy and Mechanical Properties of FDM Manufactured Parts, Proceedings of the 29th DAAAM International Symposium, pp.0210-0214, B. Katalinic (Ed.), Published by DAAAM International, ISBN 978-3-902734-20-4, ISSN 1726-9679, Vienna, Austria DOI: 10.2507/29th.daaam.proceedings.030

[3] Zha, W.; Anand, S. (2015). Geometric approaches to input file modification for part quality improvement in additive manufacturing, Journal of Manufacturing Processes, Volume 20, Part 3, October 2015, pp 465-477.

[4] Saroj, K. P.; Ranjeet, K. S.; Mahapatra, S. S.; Harish, C. D.; Anoop, K. S.; Brundaban, P. \& Mondal, A. K. (2017). Optimization of fused deposition modeling process parameters using a fuzzy inference system coupled with Taguchi philosophy, Advances in Manufacturing, Volume 5, Number 3, ISSN 2095-3127, DOI 10.1007/s40436-017-01874.

[5] Pandzic, A.; Hodzic, D. \& Milovanovic, A. (2019). Influence of Material Colour on Mechanical Properties of PLA Material in FDM Technology, Proceedings of the 30th DAAAM International Symposium, pp.0555-0561, B. Katalinic (Ed.), Published by DAAAM International, ISBN 978-3-902734- 22-8, ISSN 1726-9679, Vienna, Austria DOI: $10.2507 / 30$ th.daaam.proceedings.075

[6] Uzair, K. uz Zaman; Emilien, B.; Ali, S.; Mickael, R. \& Aamer Ahmed, B. (2018). Impact of fused deposition modeling (FDM) process parameters on strength of built parts using Taguchi's design of experiments, The International Journal of Advanced Manufacturing Technology, https://doi.org/10.1007/s00170-018-3014-6

[7] Harris, M.; Potgieter, J.; Archer, R. \& Mahmood Arif, K. (2019). Effect of Material and Process Specific Factors on the Strength of Printed Parts in Fused Filament Fabrication: A Review of Recent Developments, Materials 2019, 12, 1664; doi:10.3390/ma12101664

[8] Othman, F. M., Abbas, T. F. \& Ali, H. B. (2018). Influence of Process Parameters on Mechanical Properties and Printing Time of FDM PLA Printed Parts Using Design of Experiment, Dr. Farhad Mohammad Othman Journal of Engineering Research and Application, ISSN : 2248-9622, Vol. 8, Issue 7 (Part -II) July 2018, pp 65-69

[9] Govind, P. P. \& Parkhe, A. (2018). Parameters optimization of fused deposition modelling process for the improvement of tensile strength using Taguchi based grey relational analysis, International Journal of Advance Research, Ideas and Innovations in Technology, ISSN: 2454-132X, Impact factor: 4.295 (Volume 4, Issue 5) 